\author{
Cláudia J. Maia
}

Universidade Estadual de Montes Claros, Montes Claros, MG, Brasil

\title{
Feminismo e narrativa nacional no Brasil e em Portugal
}

\begin{abstract}
Resumo: O artigo tem como objetivo discutir a participação de escritoras feministas nas narrativas nacionais das primeiras décadas do século XX no Brasil e em Portugal, fazendo algumas interseções entre elas. Para tanto, restringi a análise às representações de gênero e de nação, construídas pela portuguesa Ana de Castro Osório e pela brasileira Júlia Lopes de Almeida nos romances epistolares Mundo Novo (1930) e Correio da Roça (1913), respectivamente. Argumento que, ao contrário da perspectiva masculina mais hegemônica de representar a nação que tende a instituir um modelo de domesticação e submissão feminina, essas escritoras construíram uma representação de nação associando o progresso desta à emancipação e independência femininas.
\end{abstract}

Palavras-chave: feminismo; gênero; nacionalismo; Ana de Castro Osório; Júlia Lopes de Almeida

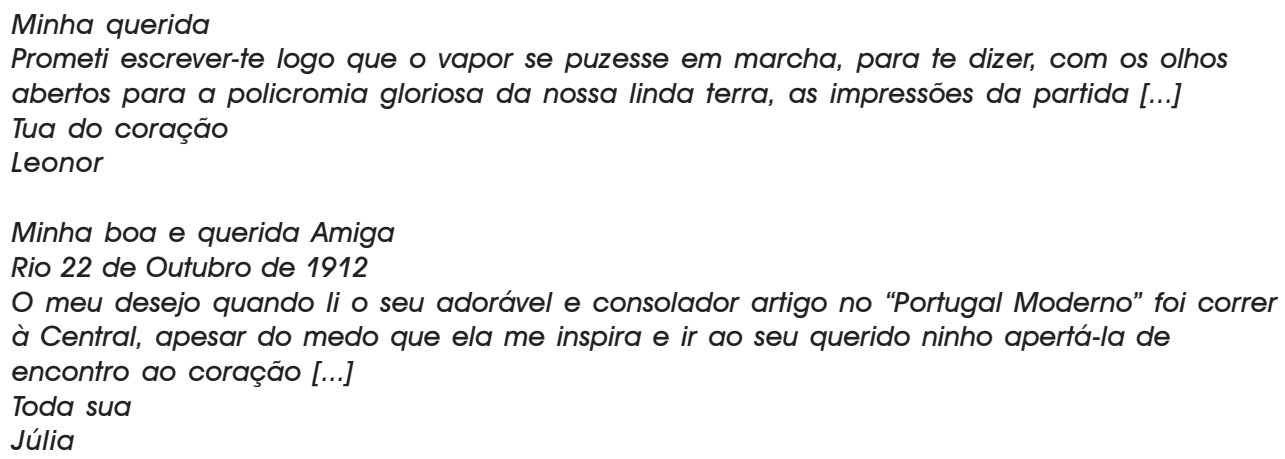

As epígrafes trazem recortes de cartas que atravessaram o Atlântico circulando notícias, ideias, sonhos, aspirações e afetos entre mulheres portuguesas e brasileiras,

\section{(c) (i)}

Esta obra está sob licença Creative Commons. 
personagens ficcionais e escritoras reais. Como enunciados elas constroem significados sobre as mulheres, as relações de gênero, o feminismo e a nação. Atenta a seus dizeres, pretendo, neste artigo, escutar e fazer ouvir as vozes de suas autoras: a feminista brasileira Júlia Lopes de Almeida e a feminista portuguesa Ana de Castro Osório. Embora importantes escritoras e personagens da cena política e literária dos seus países, elas foram, por muito tempo, silenciadas e esquecidas assim como cartas empoeiradas nos fundos dos baús. ${ }^{1}$

A atuação dessas escritoras, especialmente por meio da escrita literária, desvela em particular o intenso interesse e a participação das mulheres nas narrativas nacionais do final do século XIX e início do XX. Esse foi um período em que várias sociedades ocidentais passaram por intensas mudanças de ordem política, econômica, social e cultural, assim como nas formas de comportamento e de percepção da realidade. No Brasil e em Portugal, essas mudanças estão relacionadas especialmente à implantação do regime republicano - o Brasil em 1889, Portugal em 1910 - e à constante expansão do modo de vida burguês, com seus modelos idealizados de família, casamento, maternidade, de homens e mulheres marcados pelas diferenças de gênero. É também comum a preocupação da intelectualidade desses dois países em consolidar e em fortalecer o regime recém-criado por meio de discursos patrióticos, progressistas e de uma imagem de nação forte e próspera, embora suas estratégias representacionais sigam direções opostas: Portugal volta-se para o exterior, a fim de se afirmar como potência imperialista; o Brasil volta-se para o interior, em busca de autenticidade e explicações para os obstáculos ao progresso nacional.

A ideia de que as nações são construções imaginárias foi desenvolvida por Benedict ANDERSON (2008) em seu livro Comunidades imaginadas. Ele propôs as nações modernas como "comunidades políticas imaginadas", nascidas do colapso da ordem dinástica, concebidas como uma camaradagem horizontal e com fronteiras finitas. Uma das contribuições da abordagem de Anderson ao estudo do nacionalismo é a importância que ele atribui ao capitalismo editorial e à cultura impressa, por meio do jornal e do romance para a construção do tipo de comunidade imaginada. A cultura impressa, em especial o romance, institui sentidos e representações sobre a nação, convertendo-a numa comunidade real. Assim explica o autor:

[...] mesmo os membros da mais minúscula das nações jamais conhecerão, encontrarão, ou sequer ouvirão falar da maioria de seus companheiros, embora todos tenham em mente a imagem viva da comunhão entre eles (ANDERSON, 2008, p. 32).

Eles partilham de uma identificação comum que, não obstante, não nascem com ela, mas é discursivamente por eles elaborada. Por isso, para Stuart HALL (2006), a nação não é somente "uma entidade política mas algo que produz sentidos" (p. 49), é um sistema de representação cultural. As pessoas, argumenta esse autor, "[...] não são apenas cidadãos/ ãs legais de uma nação; elas participam da ideia da nação tal como representada em sua cultura nacional" (p. 49).

Seguindo esse argumento, podemos entender o nacionalismo como um discurso que, ao construir sentidos sobre a nação, com os quais podemos nos identificar, produz identidades nacionais, como sublinha Hall. Nessa direção, Craig CALHOUN (1997 apud Paulo César NASCIMENTO, 2003, p. 41) compreende o nacionalismo como uma formação discursiva - no sentido atribuído a esse termo por Michel Foucault. Conforme destaca Nascimento (2003), o nacionalismo, nessa perspectiva, é um discurso "que integra uma comunidade" (p. 41) e constrói uma identidade coletiva "que liga cada indivíduo

${ }^{1}$ Este artigo resulta da pesquisa de pós-doutorado realizado na Universidade Nova de Lisboa e parte na Université de Nice Shophia Antipolis, com apoio financeiro da CAPES, sob a supervisão do Prof. Manuel Lisboa e da Profa. Armanda Manguito Bouzy. 
diretamente à nação, para além da filiação deste a esta ou aquela identidade parental, étnica, religiosa ou de classe" (Idem). Assim, nesse processo de construção, como destaca Stuart Hall (2006), os discursos acionam estratégias representacionais que tendem a eliminar as diferenças de classe, raça e gênero dos sujeitos, buscando unificá-los numa única identidade cultural, "para representá-los todos como pertencendo à mesma e grande família nacional" (p. 59). No presente artigo, me interessa particularmente pensar esse processo de apagamento, exclusão e silenciamento no que se refere às mulheres, pois, como adverte Hall (2006), "[...] as identidades nacionais são fortemente generificadas" (p. 61), uma vez que seus sentidos e significados têm fortes "associações masculinas" (Idem).

A crítica feminista, ao investir sobre os discursos do nacionalismo, tem avançado as análises problematizando, dentre outras questões, o processo pelo qual as mulheres foram excluídas da "irmandade horizontal", na medida em que elas não partilham dos mesmos direitos de cidadania que os homens e tendem a ser representadas apenas como receptáculos, sujeitos passivos e incapazes; ou, ainda, desvelando suas narrativas sobre a nação silenciadas no processo histórico.

As nações modernas ocidentais tiveram como principal expressão o republicanismo, que apregoava princípios universais e igualitários; entretanto, na prática, produziu a exclusão das mulheres da esfera pública e dos direitos de cidadania. Assim, a república, como são os casos do Brasil e de Portugal, foi limitada ao imaginar a mulher como sujeito político. Conforme argumenta Mary Louise PRAT (1994), o que a república burguesa oferecia às mulheres era a "maternidade republicana", ou seja, o papel de esposas obedientes e mães abnegadas, produtoras de cidadãos, não sendo elas mesmas cidadãs. Essa autora sublinha que "a população feminina das nações não era imaginada e sequer convidada a se imaginar como parte da irmandade horizontal" (p. 131).

Não obstante, no novo cenário que se desenhou no alvorecer do século XX, com a república, as mulheres queriam participar, ser ouvidas e tomar lugar não mais como musas inspiradoras ou meras esposas reclusas e devotadas à família, mães dedicadas ou filhas obedientes, mas como trabalhadoras, intelectuais, escritoras, indivíduos jurídicos e cidadãs ativas, preocupadas com os destinos da nação. Assim, mesmo em situação desigual e desfavorável, mulheres - a exemplo de Júlia Lopes de Almeida e de Ana de Castro Osório participaram da cultura impressa de seus países como escritoras, jornalistas e leitoras, produzindo imagens de si mesmas, das outras e da nação. Mas, ao contrário da perspectiva hegemônica de representar a nação presente na literatura escrita por homens, que tende a apregoar um modelo de domesticação e submissão feminina, argumento que essas escritoras construíram uma representação de nação associando o progresso desta à emancipação e à independência femininas.

Assim, meu objetivo mais amplo é discutir algumas interseções entre o feminismo brasileiro e português das primeiras décadas do século $X X$, a partir da participação das escritoras feministas Júlia Lopes de Almeida e Ana de Castro Osório nas narrativas nacionais dos seus respectivos países. A análise é feita por meio das representações de gênero e de nação, construídas por elas nos romances epistolares Correio da Roça (1913), de autoria da brasileira, e Mundo Novo (1930), de autoria da portuguesa. O conceito de gênero é entendido aqui como uma forma primária de dar significado às relações de poder e como discurso e tecnologia social que constitui sujeitos como homens e mulheres de forma dicotômica e assimétrica (Joan SCOTT, 1995; De LAURETIS, 1994). Inicio com a análise do romance de Ana Osório e suas condições de produção; em seguida, abordo o romance de Júlia Almeida. Para concluir, apresento algumas interseções entre as duas.

Perscrutar e dar visibilidade às escritas dessas feministas contribui para romper com o monopólio masculino de produção da memória e de representação da nação; além 
disso, como sublinha Rita Terezinha SCHMIDT (2000), mostrar o país pelo olhar das escritoras possibilita "problematizar as bases das ideologias masculinas de nação" e reconceitualizar a nação "[...] como espaço heterogêneo, mais concreto e real, atravessado por tensões e diferenças" (p. 89).

\section{Ana Osório e Júlia Almeida: amizade e ativismo além e aquém mar}

Nascida em Mangualde, distrito de Viseu, em junho de 1872, em uma rica família burguesa, Ana de Castro Osório lançou-se à carreira das letras aos 23 anos com Infelizes, seu livro de estreia, em 1898. Dedicou-se à escrita de vários gêneros literários, tendo publicado inúmeros livros de contos, ensaios, romances e uma vasta obra de literatura infanto-juvenil, tornando-se uma das escritoras portuguesas mais lidas e apreciadas da sua geração. Ela também foi colaboradora em inúmeros jornais e revistas em Portugal e no Brasil. Criou a Casa Editora para as Crianças e a Edições Lusitânia. A extensa correspondência trocada com lideranças feministas, jornalistas, editores, representantes de livrarias e pessoas ligadas aos governos de diferentes estados brasileiros demonstra o enorme empenho e interesse de Ana Osório em difundir sua obra e propagar suas ideias no Brasil. Como resultado, teve dois dos seus livros de literatura infantil adotados pela instrução pública no país: Uma Lição de História, de 1909, em Minas Gerais; e Lendo e Aprendendo, de 1913, em São Paulo.

O Brasil também foi alvo de sua escrita e de seu discurso nacionalista. Entre 1911 e 1914, morou em São Paulo, acompanhando o marido, o poeta Francisco Paulino Gomes de Oliveira, cônsul de Portugal no Brasil. Nesse período, participou do Congresso de Instrução Pública, realizado em Belo Horizonte, colaborou com jornais feministas e certamente se inspirou para a escrita do livro de contos infanto-juvenil Viagens aventurosas de Felício e Felizarda ao Brasil (1917) e o romance Mundo Novo (1930), ambos ambientados no país. Em 1922, já viúva, retorna ao Brasil para participar das comemorações do primeiro centenário de independência e realizar uma série de conferências sobre a cultura e a condição das mulheres em seu país. As conferências resultaram no livro A Grande Aliança (1924), no qual a autora defende uma aliança entre Brasil e Portugal, com vistas a constituir uma raça forte para expandir a "civilização lusitana" e restituir a "glória de Portugal". Até falecer, em 1935, Ana Osório teve intensa atividade literária, cívica e política.

Como Ana Osório, Júlia Almeida também teve uma vida dedicada à carreira literária e ao ativismo político. Foi escritora talentosa e a mais conhecida da Belle époque brasileira, tornando-se a primeira mulher a tentar entrar para a Academia Brasileira de Letras e a primeira, também, a ser rechaçada. ${ }^{2}$ Iniciou sua carreira em 1881 , aos 19 anos, como articulista do jornal Gazeta de Campinas. Publicou mais de 20 livros, alguns dos quais várias vezes reeditados; escreveu romances, contos, crônicas, peças de teatro, narrativas para crianças e colaborou, por mais de 30 anos, com diversos jornais e revistas do Brasil e de países como a França e Portugal, onde também teve alguns dos seus livros publicados. Em 1914, foi homenageada em Paris por importantes intelectuais franceses e brasileiros, num evento amplamente noticiado pelos jornais tanto no Brasil quanto na França. ${ }^{3}$ Júlia nasceu no Rio de Janeiro, em 24 de setembro de 1862 e, em caminho inverso ao de Ana Osório, manteve fortes relações com Portugal. Viveu em Lisboa por três anos, onde se casou, em 1887, com o poeta e jornalista português Filinto de Almeida. Morreu em 1934.

${ }^{2}$ Sobre o processo de Júlia na ABL cf. Michele Asmar FANINI (2009). Conferir também Luca De LUCA (1999) ${ }^{3}$ O Acervo Pessoal da escritora, agora sob custódia da Academia Brasileira de Letras, reúne recortes de diversos jornais e revistas tanto do Brasil quanto da França, que noticiam por vários dias a festa em homenagem a ela em Paris, com inúmeras fotos do evento, bem como a polêmica em torno dele. 
Numa época quando, em várias partes do mundo ocidental, a educação e, sobretudo, a escrita em prosa ainda era de difícil acesso para as mulheres, tanto Ana Osório quanto Júlia Almeida conseguiram construir uma longa e profícua carreira literária. As mulheres eram vistas como incapazes de escrever e, nomeadamente, proibidas de certas leituras consideradas impróprias ou perigosas para sua formação, conforme observa Zahidé Lupinacci MUZART (2000, p. 22). Mas, ao contrário de muitas de suas contemporâneas, Ana e Júlia nasceram em ambientes familiares mais favoráveis à educação feminina e se casaram com homens também ligados ao mundo das letras, o que lhes possibilitou, não sem dificuldades ou certos limites, tornarem-se escritoras.

Entretanto, o que essas mulheres, separadas pelo Atlântico, tiveram em comum não foi somente a língua, a educação, o talento da escrita e uma rara carreira de escritoras, mas também o desejo de uma sociedade mais igualitária para as mulheres e o empenho pelo "progresso" dos seus respectivos países. Elas foram ativistas dos direitos políticos e sociais femininos, tornando-se importantes vozes do movimento feminista das três primeiras décadas do século XX em seus países.

Em Portugal, Ana Osório criou o Grupo Português de Estudos Feministas (1907); a Liga Republicana das Mulheres Portuguesas (1908) e a Associação de Propaganda Feminista (1911). Com a primeira Grande Guerra, em 1914, criou a Comissão Feminina 'Pela Pátria'; mais tarde, fundou a loja maçônica feminina Carolina Ângelo, em 1915, e ajudou a organizar, em 1916, a Cruzada das Mulheres Portuguesas (Maria José REMÉDIOS, 2004). No Brasil, Júlia Almeida participou da criação, em 1919, da Legião da Mulher Brasileira e da organização do primeiro Congresso Feminino do Brasil, em 1922. Realizou várias conferências no país e no exterior, nas quais defendia a emancipação feminina, especialmente por meio da educação (June HAHNER, 2003). Não obstante a pluralidade do feminismo desde seus primórdios, o feminismo assumido e propagandeado por essas escritoras é aquele de caráter burguês e liberal, restringindo-se, em grande parte, às reivindicações de direitos que atingiam basicamente as mulheres de elite.

Não se pode, porém, desconsiderar o potencial e a contribuição dessas feministas de elite para desconstruir efeitos de verdades e modelos femininos de submissão, passividade e futilidade predominantes na literatura escrita por homens - e nas narrativas da nação - e, portanto, mais hegemônicas. Júlia defendia a educação feminina, sendo suas protagonistas quase todas mulheres instruídas e educadas para funções que excediam àquelas restritas ao âmbito doméstico. Em suas obras, conforme observa Norma TELLES (2009), as mulheres ocupam o centro das tramas e as histórias giram quase sempre em torno do universo feminino e de personagens femininos nada convencionais; mulheres autônomas e inteligentes, embora em conformidade com o modelo de mulher burguesa, dedicadas ao lar, à maternidade e à família.

Ana Osório também defendia, em seus escritos, uma educação emancipatória para as mulheres, tanto nos livros destinados ao público adulto quanto ao público infantil, apesar de, como sugere Célia CORDEIRO (2012), ela fazer certa distinção "entre educação e instrução, numa estratégia de escalonamento das mulheres portuguesas consoante a classe social a que pertencem" (p. 81). Ana Osório foi uma das principais denunciadoras do elevado índice de analfabetismo da população portuguesa e colaborou na elaboração da lei do divórcio. ${ }^{4}$ Em sua literatura, conforme Armanda Manguito BOUZY (2012), as personagens femininas "reivindicam uma liberdade jurídica e uma credibilidade

\footnotetext{
${ }^{4}$ A lei do divórcio em Portugal é de 1910; Ana Osório colaborou com Afonso Costa na preparação dessa lei, tendo publicado, em 1911, o livro A Mulher no Casamento e no Divórcio, pela Guimarães Editores. Cópia desse livro está disponível na Biblioteca Digital da Biblioteca Nacional de Portugal, www.bnportugal.pt.
} 
profissional” (p. 9-10). Mas, assim como Júlia, predomina, na sua escrita, como modelo feminino, real e ficcional, a mulher burguesa casada, dedicada à família e à maternidade e, principalmente, responsável pelo futuro da "raça".

Júlia e Ana também fizeram parte dos círculos literários e intelectuais de seus países fortemente influenciados por ideais republicanos, positivistas, médico-higienistas em voga, e se empenharam em "imaginar" e instituir um ideal de nação.

\section{Nova Esperança: a glória de Portugal}

Mundo Novo é um romance quase todo epistolar, publicado, provavelmente, em $1922 .{ }^{5}$ Narra a história da protagonista Leonor, representação da "nova mulher" portuguesa, culta, inteligente, viajada, independente, feminista e defensora do divórcio. Leonor é também uma mulher sozinha, órfã de pai e mãe, que recebeu, de uma velha tia rica, Dona Bárbara, as condições de sua formação. Após a morte da tia, Leonor parte para o Brasil a fim de viver com o tio. No país, essa personagem passa a colaborar com o jornal Lusitano e a realizar atitudes benevolentes, se tornando uma respeitada liderança na comunidade portuguesa de imigrantes. Ao lado de outros portugueses imigrados, funda a colônia "Nova Esperança", metáfora de uma sociedade eugênica, racional e com maior igualdade de gênero.

O romance inicia com a carta de Leonor à sua amiga e confidente Regina, na qual a protagonista narra suas primeiras impressões da viagem a bordo de um navio inglês e explica os motivos de sua partida. Como se quisesse convencer a si própria, repete várias vezes: "Parte porque queres!", ou, antes, para demonstrar que Leonor - sem pai, nem marido - é uma mulher livre, que pode escolher entre partir ou permanecer, pois, como ela mesma afirma, é, aos vinte e seis anos, "única senhora e árbitra do meu destino" (OSÓRIO, 1930, p. 21). A partida de Leonor é também uma fuga a um casamento tradicional, planejado pelos pais, desde sua infância, com Miguel, pois o pretendente considera as ideias dela sobre emancipação feminina apenas "teias de aranha"; para ele, "a mulher não deveria ter direitos, de que não saberia usar e os deveres lhe bastavam para preencher os dias da existência, unicamente devotada ao homem, seu senhor..." (OSÓRIO, 1930, p. 27).

Leonor parte para fugir de uma sociedade repleta de "preconceitos esmagadores" contra as mulheres, não lhes possibilitando direitos cívicos, meios de conquistar postos de direção e seu próprio dinheiro, por isso ela busca uma sociedade mais liberta, em que o valor da pessoa é constituído pelo seu trabalho e não por seu sexo, um "Mundo Novo".

Parte, por fim, porque tem na alma "todas as fantasias aventurosas da nossa raça, queima-me o sangue de muitas gerações de emigrantes e descobridores" (OSÓRIO, 1930, p. 10). Parte, assim, em busca de fazer fortuna para assegurar sua independência financeira. Leonor tem o espírito do aventureiro de que nos fala Sérgio BUARQUE DE HOLANDA (1995) no seu clássico Raízes do Brasil. O aventureiro, ao contrário do trabalhador, "vive dos espaços ilimitados, dos projetos vastos, dos horizontes distantes" (p. 44), visa à prosperidade, mas sem esforços, prefere ousar, arriscar tudo que tem em um único negócio com a possibilidade de riqueza imediata, ao trabalho lento e laborioso. É com esse espírito aventureiro que Leonor investe todos os seus recursos em um negócio arriscado no Brasil e, com seus conhecimentos financeiros e capacidade persuasiva, convence também o tio a participar do negócio como sócio e a arriscar tudo sem medo. O negócio é bem-sucedido e Leonor rapidamente torna-se uma mulher muito rica. Cumpre-se, assim, o destino do/a aventureiro/ a português/a.

${ }^{5}$ Utilizo um exemplar disponibilizado pela Biblioteca Nacional de Portugal, catalogado como sendo de 1930; Bouzy (2012) sugere 1927 como a data provável do seu exemplar e Cordeiro (2012) indica ser 1922 o exemplar que ela utiliza e também a data da primeira edição. 
Uma das tramas do romance é o mistério em torno do testamento desaparecido de D. Bárbara, ficando toda a fortuna da moribunda para o irmão. É interessante destacar que, somente após Leonor ter ficado rica, independente e autossuficiente financeiramente, é que se desenrola a trama do testamento que a tia fez em favor da sobrinha. O que a autora deixa claro, dessa maneira, é que a protagonista se tornou rica pelos seus próprios esforços, inteligência, trabalho e coragem de arriscar, não por força externa, como a herança familiar que, nesse caso, somente deixou Leonor ainda mais rica. Outro ponto a destacar na construção sequencial do enredo é que, também, somente após Leonor ter conquistado sua independência financeira é que, finalmente, ela vai conhecer Bernardo e se apaixonar por ele. O "mocinho" só aparece no romance após percorridos dois terços da história e após muitas das tramas já terem sido desenroladas. Essa estratégia discursiva de Ana Osório vai de encontro ao pensamento de outras feministas, suas contemporâneas, que viam o amor-paixão, e, sobretudo, o casamento, como fonte de submissão e opressão feminina, por isso defendiam a educação e a independência financeira das mulheres como estratégias de escaparem à dominação masculina (Cláudia de Jesus MAIA, 2011). Entretanto, mais do que uma história de amor-paixão de um casal, Mundo Novo é uma história de amor à pátria.

Assim, o discurso, na obra, está direcionado, sobretudo, aos portugueses imigrantes, constituindo-se quase que em uma forma de doutriná-los. O texto preza mais pela propagação de ideais defendidos pela autora, com longas explicações e debates sobre temas como o feminismo, o divórcio, produção agrícola e industrial portuguesa, mas, principalmente, sobre o dever do imigrante português com a pátria, com a manutenção de tradições e pureza da raça, do que com a trama propriamente dita.

O romance de Ana Osório faz parte de uma formação discursiva específica, que é o nacionalismo europeu do final do século XIX e início do XX. Ele se soma às práticas discursivas da intelectualidade portuguesa da Primeira República, que pretendia afirmar seu projeto de nação utilizando como principal estratégia representacional a imagem de Portugal como potência colonialista e imperialista.

Segundo Élio SERPA (2000, p. 70), desde o século XIX, aos olhos das nações europeias, Portugal encontrava dificuldades em se afirmar como nação. Na Primeira República, debatia-se, internamente, em torno da sua constituição como uma nação forte e imperialista, mas, externamente, via seus interesses colonialistas ameaçados. Nesse contexto, os intelectuais portugueses procuraram, mediante diversas revistas literárias, jornais e a literatura, construir e fixar uma memória coletiva da sua tradição e mostrar aos demais países da Europa seu potencial imperialista. Para isso, utilizam como matriz discursiva a imagem de Portugal como "criador de nacionalidades", da qual o Brasil era o maior e mais concreto exemplo - tanto das realizações portuguesas, quanto para suas colônias em África. Conforme Serpa (2000), "com isso, marcavam presença no contexto das políticas colonialistas e, acima de tudo, dialogavam com o Brasil na medida em que este era o emblema da positividade da sua política colonialista [...]" (p. 70).

Essa proposta está evidente no projeto nacionalista de Ana Osório, pois uma das principais matrizes de sentido tanto em Mundo Novo quanto em A Grande Aliança é o engrandecimento do Brasil como a maior obra de Portugal; por isso, uma das estratégias na sua escrita é a utilização da história e da memória discursiva. Assim, em muitos aspectos, a saga da protagonista Leonor faz lembrar a saga de Pedro Álvares Cabral e dos bandeirantes portugueses que "descobrem"` um território vasto, fértil e inexplorado; expulsa os invasores,

${ }^{6}$ Ou demarcam e tomam a posse do território, pois, como sugere a carta de Caminha, assim como a carta deixada pela personagem D. Rosarinha, já era conhecida a existência daquela porção de terras. 
conquista os selvagens e implanta, nesse território, uma colônia portuguesa próspera, civilizada e eugênica - embora aceitem a cooperação de outros povos. Uma colônia desenvolvida econômica, social e moralmente, propagada da América do Norte a Paris, e que serve de modelo e exemplo para outras nações. Eis as palavras de Leonor:

Como vês Regina, realizei aqui alguma coisa de grande e de forte, que marcará para o futuro mais uma imposição da nossa raça [...], [e conclui]: "A cidade de Nova Esperança é apenas o exemplo do esforço que devemos realizar para a conquista civilizadora do Mundo Novo" (OSÓRIO, 1930, p. 265-266).

Nova Esperança é a representação do ideal de nação de Ana Osório. Resulta do trabalho, da bravura, da capacidade associativa e do espírito aventureiro do português, mas, sobretudo, da inteligência, da liderança e da engenhosidade feminina. Isso é explicitado e reafirmado pela autora por meio da fala de uma admiradora de Leonor: "- $E$ a senhora é que é aquela moça portuguesa que fez a propaganda da ideia e conseguiu capitais e foi quem lançou a pedra da fundação?!" (OSÓRIO, 1930, p. 351). Esse protótipo de nação imaginada por Ana Osório resulta também da cooperação e complementariedade entre os sexos, expressos no par Bernardo-Leonor. Como sócios da colônia, Bernardo se ocupa das realizações técnicas, Leonor das intelectuais e das atividades de assistência médico-social. Mas é especialmente pelo casamento, de um tipo de casamento, que Ana Osório tece o drama nacional e projeta o caminho para a consolidação da nação portuguesa.

Conforme assinalei, Ana Osório compartilha de princípios médico-higiênicos e racistas muito em voga entre os intelectuais do final do século XIX e início do XX, tanto em Portugal quanto no Brasil. ${ }^{7}$ Por isso, no romance, uma das matrizes de sentidos - dirigida especialmente ao português imigrante - é o casamento heterossexual, endogâmico, intrarracial, porém mais equitativo, no qual a mulher seja considerada sócia e não parte dominada. A mistura etnorracional é vista como perniciosa e um empecilho à constituição de um povo forte, saudável, higiênico e superior, portanto, para a consolidação de uma nação. Assim, a autora afirma várias vezes e faz reverberar que o português imigrante deve buscar uma esposa em Portugal. ${ }^{8}$

Tal argumento pode ser percebido nos enredos de casamento da personagem Angelino; do Comendador; de Bernardo e da própria Leonor. No primeiro caso, apesar dos laços afetivos entre seus empregados, Angelino - português branco imigrado - e a mulata brasileira Silvina - filha e neta da promiscuidade do senhor branco, que violenta sexualmente a escrava negra -, Leonor aconselha o rapaz a mandar buscar a costureirinha Joaninha para se casar, sob o argumento de que ela é a mulher ideal para ele, pois é portuguesa.

O Comendador, tio de Leonor, por sua vez, não buscou sua esposa em Portugal, mas se casou com a brasileira D. Flora, representação da mulher burguesa, fútil e pouco instruída. Homem bem-sucedido nos negócios e na vida pública, no âmbito doméstico vive infeliz com a esposa. D. Flora é também a representação de todos os ressentimentos dos brasileiros com seus colonizadores portugueses que, frequentemente, eram revividos em ondas de lusofobia, como naqueles anos iniciais do século XX, quando a obra foi escrita. Ela nutre raiva por Leonor e por toda herança colonial que esta evocava; por vingança contra o "sangue do marido", D. Flora colabora com a personagem Elvira no plano de esconder o

${ }^{7}$ Dentre os trabalhos sobre esse tema cf., no Brasil, Lilian SCHWARCZ (1993); Thomas SKIDMORE (1989); em Portugal, dentre outros, Rita GARNEL (2009), Ana L. PEREIRA e João Rui PITA (2011).

${ }^{8}$ Para uma discussão aprofundada sobre a concepção eugenista de Ana Osório, conferir, dentre outros, Cordeiro (2012), em especial o capítulo III: "Portugal e Brasil: Ana de Castro Osório e o papel da mulher mãe na regeneração da nação" (p. 65-80). 
testamento de D. Bárbara, a fim de prejudicar e punir Leonor. Desvelada a trama do testamento e mediante a compaixão do marido, que perdoa a esposa, D. Flora se rende aos valores e aos projetos de Leonor e o casal finalmente viverá em harmonia. O casamento do comendador com D. Flora sugere a união contratual e estratégica entre brasileiros e portugueses; entretanto, no plano consanguíneo, essa união não se concretiza, já que o casal não tem filhos, evitando, dessa maneira, a miscigenação.

O casamento de Bernardo com a italiana Berthina é, por fim, uma advertência ao português imigrado. Sem o auxílio da família, que era abastada, o jovem engenheiro português conquista fama e fortuna em terras brasileiras. O infortúnio de Bernardo começa quando ele se casa com uma mulher de outra "raça" que não a sua. A italiana Berthina é descrita como uma mulher leviana, infantil e sonhadora. Das análises possíveis desse casamento, duas me chamam mais a atenção pelas ambiguidades que elas revelam no pensamento da autora.

A primeira, como também destacou Bouzy (2012), diz respeito ao divórcio. Logo no início do romance, assim como em vários outros escritos, a autora defende o divórcio nas vozes de Leonor e da jovem feminista brasileira Antonina. Entretanto, o divórcio não aparece como solução para os problemas do casal (Bernardo e Berthina) e meio pelo qual os novos amantes (Leonor e Bernardo) pudessem ficar juntos. Assim, Leonor - rica, mas infeliz - foge do seu amor, regressando para Portugal. Em carta à amiga Regina, ela explica sua atitude: "[...] Mas sinto que não poderia resolver o problema moral doutra forma, que o orgulho do meu sangue é superior a todas as outras forças contraditórias que me solicitam" (OSÓRIO, 1930, p. 271). É o "orgulho do sangue" - não a causa e solidariedade feminina e feminista - que justifica sua decisão.

Assim, outra análise possível diz respeito ao caráter circunscrito do feminismo da autora. Na voz de Leonor, ela afirma, no início do romance: "penso que não tenho já o direito de ser egoistamente feliz, pensando que há tanta mulher neste mundo que sofre fome e sede de justiça e que eu poderei auxiliar na sua humana revolta" (OSÓRIO, 1930, p. 56). Entretanto, essa solidariedade e a defesa dos direitos das mulheres, enquanto um grupo que compartilha experiências comuns, dissipam-se quando ela atribui o fracasso do casamento de Bernardo à exogamia e, sobretudo, à esposa que assimila todos os defeitos da raça. Berthina, desprovida de "agência", é conduzida ao casamento pelos pais e manipulada ao divórcio pelo marido; a personagem vai sendo desclassificada na trama com representações negativas do feminino - mulher leviana, que abandona marido e filho - para justificar as atitudes de Bernardo. Nas palavras de Angelino, Berthina "[...] é uma mulher à toa, sem princípios, que é a vergonha daquele senhor! Ela não é nada, não tem sangue, nem um bom nome a respeitar!..." (OSÓRIO, 1930, p. 287). A defesa de princípios emancipatórios por parte de Ana Osório parece restringirse às mulheres portuguesas e àquelas pertencentes às classes mais abastadas. Com a fuga de Berthina - planejada e facilitada pelo marido Bernardo -, os amantes estão finalmente livres para concretizar o amor e desenrolar o drama nacional. Assim, Bernardo vai a Portugal buscar Leonor e eles se casam, para redenção de Bernardo e recomposição da família nos moldes tradicionais. Como marido e mulher, "os iniciadores das novas bandeiras da raça" retornam ao Brasil para continuarem, lado a lado, sua obra de "[...] penetração completa da terra brasileira" (OSÓRIO, 1930, p. 352), deixando para trás, em terras portuguesas, o filho de Berthina com Bernardo.

Por oposição ao que seria o casamento com o ex-noivo Miguel que, conforme destaca Bouzy (2012), "encarna a imagem da sociedade portuguesa organizada segundo as regras androcêntricas [...]" (p. 11) e patriarcais, o casamento de Leonor com Bernardo representa a comunhão de ideias, onde marido e mulher não estão numa relação de subordinação de um sexo pelo outro, mas são complementares. Essa maneira de pensar o casamento em 
ruptura com o ideal patriarcal presente na obra de Ana Osório é, por sua vez, característico do feminismo liberal burguês do período do qual ela participa. Por conseguinte, esse modelo de casamento aparece em Mundo Novo como símbolo também de uma nação moderna, expansiva e eugênica. ${ }^{9}$ Conforme explica Cordeiro (2012), a responsabilidade que Ana Osório atribui à mulher portuguesa

pela pureza ou integridade racial do povo português dos dois lados do Atlântico, percorre a ideologia positivista tipicamente republicana do período, que marca indelevelmente o ideário feminista português (p. 79-80).

Somente a mulher portuguesa seria "capaz de reerguer Portugal como potência imperial europeia" (p. 79-80).

Em Mundo Novo, o feminismo, representado pelos discursos emancipatórios das mulheres, emerge como instrumento do nacionalismo de Ana Osório. Ele não é o fim, mas um dos caminhos defendidos pela autora para Portugal realizar "o ideal da raça". Nova Esperança é o protótipo desse ideal, que só foi possível porque Leonor é uma mulher livre, independente financeiramente, bem instruída e, acima de tudo, portuguesa. Bernardo já havia tentado encontrar o território perdido e fundar a colônia, mas fracassou na sua tentativa. Ele só conseguiu ao lado de Leonor, não de Berthina. Mas é preciso destacar que Nova Esperança foi sonho e projeção masculina, ou seja, de Bernardo, que a mulher, Leonor, tornou possível. A defesa da equidade entre os gêneros se dá em função dos papéis que ambos devem cumprir a favor da pátria. Leonor, representação da portuguesa moderna e emancipada, é a agente de regeneração da raça, da civilização e da instituição da nação.

Rosi BRAIDOTTI (2002), ao analisar o nacionalismo europeu no contexto da pósmodernidade, lembra que "a pretensão universalista da Europa, ligada ao seu passado colonial - é baseada no poder e potência simbólica das nações-Estado" (p. 6) que entraram em declínio com a economia transnacional. Esse declínio da nação-Estado europeia, conforme destaca Braidotti (2002),

[...] também marca a crise histórica dos valores que representavam principalmente a autoridade masculina fundada e personificada na família patriarcal, na heterossexualidade compulsória e na troca de mulheres - todos articulados do outro lado do cadinho da masculinidade (p. 6).

Tal percepção elucida a posição contraditória de Ana Osório, que procura afirmar o lugar do feminino, mas sem romper radicalmente o discurso masculino de nação; ou seja, de dentro de uma formação discursiva específica, que é o nacionalismo europeu daquele início de século. A análise de Braidotti possibilita perceber, por sua vez, o discurso de Júlia Lopes de Almeida sobre a posição das mulheres na nação um pouco mais subversivo dos valores patriarcais, uma vez que, longe de um passado colonialista glorioso a ser reafirmado, o discurso nacionalista brasileiro - do qual ela participa - se constitui a partir de outras matrizes discursivas.

\section{O progresso da mulher e do campo brasileiros}

Se o projeto de nação de Ana Osório e de intelectuais portugueses da Primeira República voltava-se para as questões externas, buscando reafirmar os laços coloniais

\footnotetext{
${ }^{9}$ A forma como Ana Osório pensa o casamento e a família contesta e questiona aquela proposta por alguns intelectuais do final do século XIX e início do XX em Portugal. Conforme Irene VAQUINHAS (2011), a família, no pensamento de autores como Alves Ribeiro, era concebida como "uma forma proto-histórica de nação à [sic] qual fornece o modelo de organização política a adoptar pelo Estado" (p. 123), onde o pai/marido exerce poderes de um monarca.
} 
com o Brasil, em sentido contrário, a intelectualidade brasileira, ao imaginar sua comunidade nacional, voltava-se para as questões internas, procurando distanciar-se e, até mesmo, apagar seu passado comum com Portugal, a fim de afirmar sua autonomia, originalidade e autenticidade.

A busca de elementos que explicassem o Brasil com vistas à construção de uma identidade nacional remonta ao período subsequente à independência. Entretanto, a República, imbuída de princípios nacionalistas, recoloca a necessidade de identificar os obstáculos que impediam o Brasil de se constituir como uma nação forte e civilizada. Muitos intelectuais se voltaram para o interior do país de modo a identificar os males e "traços negativos" responsáveis pelo atraso. Segundo Nísia LIMA e Gilberto HOCHMAN (2000), alguns o atribuíam à "herança ibérica com sua tradição estadista e pouco propensa à iniciativa individual"; outros à composição etnorracial da população com a predominância de raças inferiores e mestiças (LIMA; HOCHMAN, 2000). Assim, conforme destacam esses autores, questões como raça e herança colonial reassumiam crescente importância nas controvérsias que marcam o debate em torno da questão nacional no final do século XIX e nas três primeiras décadas do século XX (LIMA; HOCHMAN, 2000). Com a expansão do discurso médico-higienista, a doença emerge como o principal obstáculo ao progresso nacional e à civilização do povo; o brasileiro era percebido, dessa maneira, como preguiçoso, indolente, melancólico, resistente a mudanças. Era preciso sanear, higienizar, regenerar a população. Esse discurso justificou as campanhas sanitaristas, projetos de higienização e vacinação obrigatória do período (lbidem. Cf., também, FERREIRA, 2014; Nicolau SEVCENKO, 1998).

A literatura, enquanto prática discursiva, foi importante para a instituição de tais representações. Assim, o personagem Jeca-Tatu, de Monteiro Lobato, sintetiza a imagem construída do brasileiro do campo como homem preguiçoso e doente, responsável pelo atraso nacional; imagem que necessitava ser superada para consolidação da nação. Conforme Ermelinda Maria FERREIRA (2014), "a 'causa' da passividade do brasileiro do campo encontra finalmente uma explicação - a doença -, e uma esperança de cura pela educação, adoção de hábitos de higiene e mudança de hábitos alimentares" (p. 197).

O Correio da Roça é um dos discursos que compartilha, institui e faz circular tais sentidos e explicações sobre o Brasil e o brasileiro. Esse drama da questão nacional é, sem dúvida, o tema central do romance, a partir do qual Júlia participa e constrói um ideal de nação. Entretanto, no romance, é a mulher, mais precisamente a mulher do campo e a mulher burguesa instruída, a agente da regeneração e do progresso nacional.

Correio da Roça é um romance epistolar, publicado em livro em 1913; pela estratégia de escrita, indica ser dirigido especialmente às populações rurais brasileiras. Segundo Marly Jean VIEIRA (2011), esse foi um dos romances de grande repercussão de Júlia, sendo "reeditado várias vezes e adotado em escolas agrícolas do país" (p. 1873).

Por meio das cartas de Fernanda à sua amiga Maria, a autora transmite instruções de higiene, cultivo agrícola, construções rurais, jardinagem, abertura e conservação de estradas, educação no campo, comércio, administração rural, economia doméstica etc., e conscientiza a mulher do campo sobre a importância do seu papel para o progresso nacional, pois "[...] a lavradora mais do que outra qualquer mulher pode exercer no Brazil uma influência benéfica sobre tudo que a rodeia [...]" (ALMEIDA, 1913, p. 115).

O romance narra a história de Maria, uma senhora burguesa da sociedade carioca que, após a morte do marido, vê-se falida e pobre, restando como único patrimônio a fazenda Remanso, que agrega o sítio Tapera, herdado dos pais. Maria é obrigada a se mudar com as quatro filhas: Cecília, Cordélia, Joaninha e Clara para a fazenda, de onde inicia sua longa correspondência com Fernanda. 
A fazenda Remanso e o sítio Tapera são a imagem do Brasil decaído, pobre, devastado e atrasado, resultado da preguiça, da falta de higiene e da resistência às mudanças do homem do campo, representado pela figura do caboclo ignorante, inculto e incivilizado. Maria descreve à Fernanda como encontrou o sítio Tapera:

[...] A casa desmorona-se. Há buracos pelas paredes, por onde entram vento e a chuva, sem que o casal de caboclos se tivesse lembrado de entupi-los com uma passada de barro, ao menos... Corri ao laranjal! Onde estaria?

A erva de passarinho comera-o todo. O cafezal está em mato. Os canaviais extintos.. Dentro de casa - nudez completa: os caboclos nem ao menos uma das camas souberam guardar para seu uso [...] (ALMEIDA, 1913, p. 115).

Entretanto, com o trabalho de Maria e das quatro filhas, instruídas pela amiga Fernanda, a fazenda - assim como os moradores do seu entorno - passam por um profundo processo de regeneração e civilização, ressurgindo como uma fazenda próspera, moderna, racional, higiênica; com cultivo e criação de várias espécies, estradas bem construídas para escoar a produção, escola e um grande hospital, servindo de modelo para toda a vizinhança. A fazenda é o protótipo do Brasil que deveria também passar por tal metamorfose para se constituir como nação. Nesse processo de imaginação nacional, é a mulher bem instruída a agente de regeneração e do progresso, como foi apontado anteriormente.

Fernanda, a principal mentora desse projeto, vive no Rio de Janeiro; é uma senhora culta, bem instruída, com conhecimentos que vão de comércio internacional à economia doméstica e possui uma pródiga imaginação. Para auxiliar Maria a introduzir princípios de racionalidade no cultivo agrícola e na administração da fazenda, ela se informa, pesquisa e estuda, conforme explica à amiga em sua missiva: "Percebi toda a vida que meu marido gostaria muito que eu tivesse um pouco menos de imaginação; mas essa vontade é talvez a única que eu nunca lhe pude fazer!" (ALMEIDA, 1913, p. 146).

É por meio de Fernanda que Júlia apresenta sua crítica à educação feminina e ao modelo de mulher burguesa passiva, fútil, pouco instruída, avessa ao trabalho, que também deve ser superado. Na primeira carta que Maria escreve à Fernanda, ela relata sua mudança para Remanso, lamenta sua situação de penúria e das filhas sem ocupação e se pergunta: "De que Ihe valerão agora as prendas com que se ornaram para brilhar na sociedade?". E, num "P.S.", Maria solicita à amiga que Ihes envie um "bom jornal de modas parisienses" para ter com que se distrair e ocupar (ALMEIDA, 1913, p. 8-9).

Em resposta, Fernanda diz: "É com certeza por modéstia que te lamentas da escassez de meios, tendo a rodear-te quatro cabeças inteligentes, oito braços fortes e à tua disposição não sei quantos quilômetros de terras...", e continua ela: em vez de jornais de moda, "assina de preferencia revistas agrícolas instrutivas, alegres, que lhes deem noções aproveitáveis de industrias campestres [...]", em vez do folhetim-romance ou das fofocas de sociedade, "[...] obriga as tuas filhas a lerem os jornais todos os dias, sem desprezo por certas noticias [...]". No lugar de cultivarem saudades dos saraus e avenidas do Rio, "antes cultivassem batatas" (ALMEIDA, 1913, p. 10-15). Assim, sem piedade ou vitimizar as amigas, Fernanda passa a indicar uma ocupação para cada uma das filhas: cultivo de batatas, flores, criatório de aves etc., e conclui:

[...] aproveita essa circunstancia em favor da outra, a de veres tuas filhas interessadas pelo progresso e a redenção das terras abandonadas em que vivem e pela civilização dessa gente do povo que Ihes rodeia a fazenda e que vegeta mais do que vive sem proveito nem gloria para o Brasil nem para si. [...] sei de que milagres é capaz a inteligência e a energia das mulheres obrigadas a atuarem por si (ALMEIDA, 1913, p. 15-16 [grifos meus]). 
Passado o choque das duras palavras da amiga, aos poucos as filhas vão se interessar cada uma por uma atividade produtiva e social da fazenda e, sempre aconselhadas por Fernanda, fazem seus negócios prosperarem. Criam uma escola, um coral, um hospital; rearborizam a fazenda. Diferentemente dos discursos, sobretudo os discursos médicos do período, que buscavam circunscrever o movimento das mulheres e os limites dos seus corpos, as personagens de Júlia desfrutam de autonomia para ir e vir por toda parte e as atividades laborativas não aparecem incompatíveis com seus corpos; pelo contrário, eles possuem certo vigor para o trabalho. Ao relatar o progresso da fazenda, Maria explica: "dei inteira liberdade de ação às minhas filhas [...]" (ALMEIDA, 1913, p. 138), tanto de movimentos, quanto de exercício de suas escolhas. O sentido que emerge na construção dessas personagens é que, para o progresso da fazenda, assim como para o do Brasil, é preciso um novo modelo de mulher que tenha educação e liberdade.

Entretanto, não se pode deixar de observar que os "negócios" recomendados por Fernanda e desenvolvidos pelas filhas de Maria não são aqueles mais expressivos da esfera produtiva de uma fazenda; não é o cultivo de produtos de grande valor no mercado ou a criação de animais de grande porte, atividades frequentemente associadas à esfera de atuação masculina no meio rural. As atividades que as jovens fazem prosperar são aquelas mais próximas do universo feminino, como o cultivo de flores, hortas, criação de animais de pequeno porte, atividades relacionadas à assistência e ao cuidado com o outro, tais como o ensino, a enfermagem, o trabalho artístico. Se, por um lado, a autora rompe com representações de gênero tradicionais ou que estão sendo instituídas relativas às mulheres, por outro, ela corrobora outras, como a divisão sexual do trabalho típica do meio rural.

Mas, como no enredo de Ana Osório, somente após as personagens femininas conquistarem sua independência e se realizarem nas ocupações escolhidas é que aparece na trama um par romântico para as filhas mais velhas, Cecília e Cordélia. Não por acaso, um agrônomo e um engenheiro - símbolos da racionalidade científica no campo-com os quais as jovens irão se casar e dar continuidade ao projeto de redenção do campo brasileiro. Dessa forma, o modelo de mulher burguesa fútil cede lugar ao modelo de uma nova mulher, defendido e apresentado pela autora como símbolo do progresso nacional. Ou seja, uma mulher que possui uma ocupação produtiva e social, educada, casada e livre. Um modelo a ser seguido pelas outras, como a autora sugere na voz de Fernanda: "É desses empenhos que os nossos sertões precisam: mulheres que vos imitem [...]" (ALMEIDA, 1913, p. 166).

\section{Leituras cruzadas}

Ao estudar as representações de nação na literatura de autoria feminina, Débora FERREIRA nota que "muitas escritoras compartilhavam de uma percepção da história/ sociedade subversiva à versão oficial" (FERREIRA, 2004, p. 27), ${ }^{10}$ construindo, em seus textos literários, representações diferenciadas da nação. Assim, uma das características dessa literatura é primar por relações horizontais entre a protagonista e as outras mulheres da trama. Conforme sublinha essa autora, "os papéis masculinos, de pai, irmão, marido, dentre outros, são fracos ou inexistentes, sugerindo um universo com tênues normas patriarcais. As protagonistas são então, em geral, sem maridos ou filhos" (FERREIRA, 2004, p. 27). Essa característica está presente também nas obras das escritoras aqui estudadas. Tanto em Mundo Novo, quanto no Correio da Roça, as personagens masculinas são secundárias e pouco expressivas nas tramas; as protagonistas são mulheres sozinhas que, embora se casem no final, como no caso de Leonor, Cecília e Cordélia, isso ocorre somente após

${ }^{10}$ Sobre esse tema, ver também Margareth RAGO (2005). 
realizarem seus projetos pessoais e conquistarem sua independência financeira. Além das histórias das protagonistas, outras histórias de mulheres, quase sempre de opressão e injustiça, são tecidas nas tramas, especialmente no romance de Ana Osório.

Alguns outros pontos são comuns nos romances de Ana e Júlia: ambos são epistolares; a crítica à educação feminina pouco instrutiva; a crítica à mulher burguesa, fútil e passiva, como modelo a ser suplantado; a defesa de produtos nacionais. Embora falem, sobretudo, para as mulheres, ambas direcionam seu discurso a um sujeito específico: o imigrante português, no caso de Ana Osório, e o homem do campo, no caso de Júlia Almeida; a importância que atribuem à amizade entre mulheres - Leonor-Regina, Maria-Fernanda ao contrário da tendência de serem representadas em literaturas e discursos de autoria masculina quase sempre como rivais.

Outro ponto semelhante a destacar é que as duas histórias iniciam com mulheres sozinhas (uma viúva, outra solteira) que partem para um novo destino: Leonor para o exterior, o Brasil; Maria, em direção oposta, para o interior, a fazenda Remanso. As autoras indicam, assim, logo no início de seus romances, a direção que suas pátrias deveriam seguir para percorrer seu caminho de progresso e atingir seu novo destino como nações consolidadas.

Ana Osório, ao contrário de Júlia, deixa explícitas em seu texto suas posições a favor do feminismo, do divórcio, de princípios racistas e eugênicos, assumindo um nacionalismo muito mais exacerbado. Júlia, embora construa seus argumentos do progresso nacional a partir de princípios higienistas, considerando o caboclo "incivilizado" e "atrasado", não assume posições eugênicas como sua amiga.

Mas, tanto no projeto de Júlia, quanto de Ana, é a mulher o agente de regeneração e de civilização da nação. Mariette SINEAU (1994) lembra que a mulher, enquanto potência civilizadora, "anunciadora de novos valores e de novos modelos", está historicamente presente em certas concepções feministas, em especial no movimento sufragista do início do século XX. Na França e na Inglaterra, conforme exemplifica essa autora, as sufragistas acreditavam "[...] enormemente no poder transformador que representa a identidade, a alteridade feminina (a mulher é 'o outro') face ao mundo dos homens" (p. 73). ${ }^{11}$ Essa perspectiva é assumida por Ana Osório e Júlia Almeida; assim, nas obras aqui analisadas, a protagonista é também o ícone do progresso nacional, e tem deveres a cumprir com a pátria. Entretanto, seu dever não é como mãe abnegada ou esposa obediente do novo cidadão. Ela não é "imaginada" a partir de modelos de submissão, mas é revestida de agência e reclama para si independência financeira, educação, direitos e liberdade. Retomando, então, a hipótese que apresentei inicialmente, posso agora afirmar que essas escritoras construíram representações de nação, associando seu progresso à independência feminina.

Embora o feminismo de Ana Osório e o de Júlia Lopes de Almeida seja mais moderado e elas reivindiquem uma autonomia feminina, ainda dentro do modelo burguês e da heterossexualidade compulsória, não se pode negar a importância dessas escritoras para o pensamento feminista das primeiras décadas do século XX em Portugal e no Brasil. Elas fizeram de sua literatura um campo aberto para o debate em torno da condição feminina. Questionaram os papéis e lugares subalternos e passivos reservados às mulheres na cultura patriarcal e produziram novas representações sobre as mulheres, seus corpos, trabalho e independência, oferecendo a elas imagens mais positivas de identificação. Elas fizeram da escrita literária um ato político e uma estratégia de liberdade e de luta das mulheres.

${ }^{11}$ No original: "[...] les suffragettes croient énormément au pouvoir transformateur que représente l'identité, l'altérité féminine (la femme, c'est "l'autre") face au monde des hommes". 


\section{Referências}

ALMEIDA, Júlia Lopes. Correio da Roça. Rio de Janeiro: Francisco Alves, 1913.

ANDERSON, Benedict. Comunidades imaginadas. São Paulo: Cia das Letras, 2008.

BNL. Espólio CASTRO OSÓRIO. Carta de Júlia Lopes de Almeida a Ana de Castro Osório, Rio de Janeiro, 22 de outubro de 1912.

BOUZY, Armanda Manguito. "Representações da mulher em obras de Ana de Castro Osório e Maria Archer: a (des)construção do estereótipo". In: CONGRESSO INTERNACIONAL DE CULTURA LUSOFÓNICA CONTEMPORÂNEA. Portalegre (PT), Anais, 2012.

BRAIDOTTI, Rosi. "Diferença, diversidade e subjetividade Nômade". Labrys: estudos feministas, n. 1, v. 1, p. 130-151, 2002.

BUARQUE DE HOLANDA, Sérgio. Raízes do Brasil. São Paulo: Companhia das Letras, 1995.

CALHOUN, Craig. Nationalism. Minneapolis: University of Minnesota Press, 1997.

CORDEIRO, Célia Carmen. Ana de Castro Osório e a mulher Republicana Portuguesa: veículo de regeneração da nação e de preservação da identidade Nacional. Lisboa: Fonte da Palavra, 2012.

DE LAURETIS, Teresa. "A Tecnologia do gênero". In: HOLLANDA, Heloísa Buarque de (Org.). Tendências e impasses: o feminismo como crítica da cultura. Rio de Janeiro: Rocco, 1994. p. 206-242.

DE LUCA, Luca. "O "feminismo possível" de Júlia Lopes de Almeida". Cadernos Pagu, Campinas, Unicamp, n. 12, p. 275-299, 1999. Disponível em: file://C:/Users/Toshiba/ Downloads/cadpagu_1999_12_18_LUCA.pdf. Acesso em: 30/08/2016.

FANINI, Michele Asmar. "Júlia Lōpes de Almeida: entre o salão literário e a antessala da Academia Brasileira de Letras". Estudos de Sociologia, Araraquara, v. 14, n. 27, p. 317 338, 2009.

FERREIRA, Débora R. S. Pilares Narrativos. Ilha de Santa Catarina: Mulheres, 2004.

FERREIRA, Ermelinda M. A. "Os males do Brasil são: a doença como elemento distintivo da condição de ser brasileiro". Estudos de Llteratura Brasileira Contemporânea, n. 43, p. 193-212, 2014.

GARNEL, Rita. "Portugal e as Conferências Sanitárias Internacionais (em torno das epidemias oitocentistas de cholera-morbus)". Revista de História da Sociedade e da Cultura, Lisboa, n. 9, p. 229-251, 2009.

HAHNER, June E. Emancipação do sexo feminino: a luta pelos direitos da mulher no Brasil, 1850-1940. Florianópolis: Mulheres, 2003.

HALL, Stuart. A identidade cultural na pós-modernidade. Rio de Janeiro: DP\&A, 2006.

LIMA, Nísia T.; HOCHMAN, Gilberto. "Pouca saúde, muita saúva, os males do Brasil são... Discurso médico-sanitário e interpretação do Brasil”. Ciência \& Saúde Coletiva, v. 5, n. 2, p. 313-332, 2000.

MAIA, Cláudia de Jesus. A invenção da solteirona: conjugalidade moderna e terror moral. Florianópolis: Mulheres, 2011.

MUZART, Zahidé Lupinacci. "Pedantes e bas-bleus: uma história de uma pesquisa". In:

(Org.). Escritoras brasileiras do século XIX. Florianópolis: Mulheres, 2000. p. 17-29.

NASCIMENTO, Paulo César. "Dilemas do Nacionalismo". BIB, São Paulo, n. 56, p. 33-53, 2003.

OSÓRIO, Ana de Castro. A Grande Aliança. Lisboa: Instituto Piaget, 1997. . Infelizes: histórias vividas. Lisboa: Libânio \& Cunha, 1898.

. Lendo e Aprendendo. São Paulo: Empreza de Propaganda Literaria Luso-Brasileira, 1913.

Mundo Novo. Porto: Companhia Portuguesa Editora, 1930.

Uma Lição de Historia. Setúbal: Livraria Editora 'Para as Crianças', 1909. 
Viagens aventurosas de Felício e Felizarda ao Brasil: Contos para crianças. Lisboa: Lusitania Ed., 1923.

PEREIRA, Ana L.; PITA, João Rui. "A higiene: da higiene das habitações ao asseio pessoal". In: VAQUINHAS, Irene (Coord.). História da Vida Privada em Portugal. A Época Contemporânea. Lisboa: Circulo de Leitores e Temas e Debates, 201 1. p. 92-116.

PRATT, Mary Louise. "Mulher, literatura e irmandade nacional". In: HOLLANDA, Heloísa B. de (Org.). Tendências e impasses: o feminismo como crítica da cultura. Rio de Janeiro: Rocco, 1994. p. 127-157.

RAGO, Margareth. "Cultura feminina e tradição literária no Brasil (1900-1932)". In: NAVARROSWAIN, Tânia; MUNIZ, Diva C. G. (Orgs.). Mulheres em Ação: práticas discursivas, práticas políticas. Florianópolis: Mulheres; Belo Horizonte: PUC Minas, 2005. p. 195-216.

REMÉDIOS, Maria José. "Ana de Castro Osório e a construção da Grande Aliança entre os povos: dois manuais da escritora portuguesa adoptados no Brasil". Faces de Eva, Lisboa, Colibri/UNL, n. 12, p. 91-106, 2004.

SCHMIDT, Rita Terezinha. "Mulheres reescrevendo a nação". Revista Estudos Feministas, v. 8, n. 1, p. 84-97, jan.-jun. 2000.

SCHWARCZ, Lilian. M. O Espetáculo das raças: cientistas, instituições e questão racial no Brasil, 1870-1930. São Paulo: Cia das Letras, 1993.

SCOIT, Joan. "Gênero: uma categoria útil de análise histórica". Educação e Realidade, v. 20, n. 2, p. 71-99, 1995.

SERPA, Élio. "Portugal no Brasil: a escrita dos irmãos desavindos". Revista Brasileira de História, São Paulo, v. 20, n. 39, p. 69-97, 2000.

SEVCENKO, Nicolau. "Introdução. O prelúdio republicano, astúcias da ordem e ilusões do progresso". In: (Org.). História da vida privada no Brasil 3. República: da Belle Époque à Era do Rádio. São Paulo: Cia das Letras, 1998. p. 7-48.

SINEAU, Mariette. "Femmes et culture politique. Nouvelles valeurs, nouveaux modèles?". Vingtième Siècle. Revue d'histoire, n. 44, p. 72-78, oct./déc. 1994.

SKIDMORE, Thomas. Preto no Branco. Rio de Janeiro: Paz e Terra, 1989.

TELLES, Norma. "Introdução a Família Medeiros". In: ALMEIDA, Júlia Lopes. A Família Medeiros. Florianópolis: Mulheres, 2009. p. 11-26.

VAQUINHAS, Irene. A família, essa "pátria em miniatura". In: História da Vida Privada em Portugal. A Época Contemporânea. Lisboa: Circulo de Leitores e Temas e Debates, 2011, p.118-151.

VIEIRA, Marly Jean de A. P. "A literatura feminista de Júlia Lopes de Almeida". In: XIV SEMINÁRIO NACIONAL MULHER E LITERATURA. Brasília, Anais, 2011.

[Recebido em 27/1 1/2015,

reapresentado em 04/09/2016

e aprovado em 01/03/2017]

\section{Feminism and National Narrative in Brazil and Portugal}

Abstract: The article has as its broader objective to discuss the participation of feminist writers in the national narratives of the first decades of the twentieth century in Brazil and Portugal, making some intersections between them. To this purpose, I have restricted the analysis to the representations of gender and nation built by the Portuguese Ana de Castro Osório and Brazilian Júlia Lopes de Almeida in the epistolary novels Mundo Novo (1930) and O Correio da Roça (1913), respectively. I argument that, unlike the more hegemonic male perspective of representing the nation which tends to establish a model of female domestication and submission, those writers built a representation of nation associating its progress with women's emancipation and independence.

Keywords: Feminism; Gender; Nationalism; Ana de Castro Osório; Júlia Lopes de Almeida 
Cláudia J. Maia (cjmaia@gmail.com) é professora adjunta do Departamento de História da Universidade Estadual de Montes Claros (Unimontes); coordenadora do Grupo de Pesquisa Gênero e Violência (CNPq). Doutora em História pela UnB (2007) com período sanduíche na École des Hautes Études en Sciências Sociales (Paris); pós-doutorado na Universidade Nova de Lisboa com período na Université de Nice Sophia Antipolis. 